future of European experiments for the NASA vehicle. According to ESA, work on those experiments is already well advanced and substantial sums of money, which will have been spent in vain if NASA's decision stands, have already been committed. The total cost to completion of the two spacecraft is an estimated $\$ 140$ million, $\$ 100$ million of which is already accounted for.

Judy Redfearn

\section{European fusion}

\section{JET's ambition}

JET, the joint European tokamak nuclear fusion experiment, may cost another 400 million European units of account (EVA) ( $£ 216$ million) if first the JET Council - which oversees the project - and then the European Commission agree. The money would be spent over five years, beginning in 1982, and would extend JET to its full design performance, including bulk ignition of a deuteriumtritium plasma. "If they want the results, they'll have to pay" said Dr Hans-Otto Wüster, director of JET, of the European governments last week.

The original cost of basic JET was 185 million EUA at January 1977 prices. Inflation in Britain, coupled with the strength of the pound sterling and a serious underestimate of the cost of diagnostic equipment, has pushed that basic price to something nearer 300 million EUA; but even so the proposed extension would more than double the total cost. Dr Wuster, however, points out that the extra cost is only twice the annual budget of the CERN laboratory in Geneva.

The rush to extend JET is occasioned by two factors. First, machines like JET seem to have a better chance of reaching ignition, the nuclear burning of the plasma, than when they were designed in the early 1970s. Second, the European Council of Ministers has asked for a proposal for fusion research in Europe for the next five-year period, 1982-86, by 1 July this year.

Competition with the United States is also in mind. Princeton's Tokamak Fusion Test Reactor is due to begin experiments in 1982 , and the somewhat larger JET in early

\section{JET upgraded}

The extension of JET to full design performance would involve increased magnetic confinement fields, additional heating of the plasma, facilities for storing and handling tritium, and remote handling equipment for experiments. Specifically, the peak toroidal field coil power would be increased from $250 \mathrm{MW}$ to $380 \mathrm{MW}$; total magnetic field at plasma centre $27.7 \mathrm{kG}$ to $34.5 \mathrm{kG}$; plasma current from 3.8 MA to 4.8 MA; and additional heating power from 4-10 MW to $25 \mathrm{MW}$.

Robert Walgate
1983. Princeton is being pushed hard by the US Department of Energy to try ignition early. If all went well, JET's initial nonnuclear plasma experiments would then look pretty tame. On the other hand, if either laboratory is too hasty in introducing radioactive tritium, repeating early experiments will be very difficult, requiring remote handling and radiation protection.

Important plasma physics problems remain to be solved. Present optimism arises because two predicted limits on plasma containment have not been observed in existing small tokamaks. "Trapped particle instabilities" were expected to set in at temperatures above 30 million $K$, but the smaller Princeton tokamak has reached 70 million $\mathrm{K}$ without seeing them. And the ratio of plasma pressure to magnetic pressure was thought to be limited to about 1 per cent, but values of 8-9 per cent have been reached. While experimentally encouraging, these results are theoretically puzzling, so the JET and Tokamak Fusion Test Reactor regions may still hold surprises.

Dr Wüster is therefore cautious, offering 3-4 years of plasma at JET before attempting ignition around 1987. But the bulk of the spending on "extended performance" would have to be undertaken in 1982-86. In January, the JET Council gave Wüster a 400 million EUA guideline for the extended performance, and asked him to say what he could do with that. If, this month, his proposals are adopted, it will be for the European Commission to consider whether to include it as part of the 1982-86 research programme.

Conflicts between the interests of the national laboratories and money-hungry JET seem likely to be resolved at JET Council level; but the commission must also test the interest of governments, for which reason it has set up a new committee - the Consultative Committee for Fusion Programmes - which will be dominated by the representatives of government departments from whose coffers the money must ultimately be found.

The commission has also established an expert panel, the European Fusion Review Panel, to make recommendations for a long-term programme, beyond the present generation of machines. This panel will also report to the commission before July, in time to influence the final commission proposal.

One question to be dealt with is whether Europe is wise to commit itself so heavily to one design of fusion device, the tokamak. In the United States, there is also substantial work on the potentially simpler magnetic mirror confinement and inertial confinement. Wüster says that it makes sense to push ahead with the device that will most quickly yield ignition, so as to win practical experience of the problems of operating fusion reactors of all types. We shall see whether the European Fusion Review Panel agrees with him.

\section{United States budget}

\section{More cuts}

\section{Washington}

True to its political convictions, when full details of its proposed budget cuts are announced next week, the Reagan Administration is expected to eliminate virtually all the federally sponsored programmes initiated by President Carter to stimulate innovation in private industry.

President Carter's initiatives were the result of a broad-ranging, eighteen-month study largely instigated by the Office of Science and Technology Policy. Recommendations were made by eight independent advisory committees, and submitted to the White House with proposals from individual federal agencies.

From these, a package of 32 proposals was eventually accepted and announced by $\mathrm{Mr}$ Carter in November 1979. Although criticized at the time for not going far enough, it was generally agreed that the proposals made up a modest set of experimental and exploratory approaches aimed at bringing industry, government and the universities closer together.

The interventionist approach which the new programmes embodied, however, has found little sympathy with the new Administration, which sees its principal strategy for stimulating innovation as improving the financial incentives for investment, not direct federal participation.

The Administration will therefore be expected to drop support for any future cooperative generic technology centres, even though specific legislation setting up these centres was approved by Congress last year, and $\$ 5$ million allocated to their support (Nature 286, 195; 1980). From the three centres initially proposed, only one, in Detroit, is likely to survive as plans were agreed before the election, although even this is uncertain since it will depend on the centre's ability to raise matching funds from industry.

Other projects previously under development in the Commerce Department and now expected to be phased out include proposals to establish state-based Corporations for Innovation Development to help entrepreneurs gain access to investment capital, and the new Office of Technology Strategy and Evaluation.

It is also rumoured that the new Administration may not seek a successor to Dr Baruch, who as Assistant Secretary for Productivity Technology and Innovation was responsible for science and technology programmes within the department. This would be opposed by Congress, which spent much time last year discussing the Carter Administration's initiatives, and supported their general thrust.

Another of Mr Carter's initiatives which will be overruled is the Co-operative Automotive Research Project (CARP), originally proposed by Transportation Secretary Mr Brock Adams as a means of 